\title{
Assessment of Genetic Diversity among Fenugreek (Trigonella foenum-graecum L.) Genotypes using ISSR Markers
}

\author{
N.C. Mamatha*, S.K. Tehlan, M. Srikanth, T. Ravikumar, \\ Shikha Yashveer and Mukesh Kumar
}

\author{
Department of Vegetable Science, CCS Haryana Agricultural University, Hisar-125004, India \\ *Corresponding author
}

\begin{tabular}{|c|c|}
\hline & A B S T R A C T \\
\hline & \multirow{5}{*}{$\begin{array}{l}\text { Fenugreek [Trigonella foenum-graecum L.] is an annual herb of Leguminaceae family and is largely } \\
\text { cultivated in warm temperate and tropical regions. The presence of variability in breeding population } \\
\text { is prior need for crop improvement. This calls for an evaluation of genotypes to study the variability. } \\
\text { The study was conducted to reveal the genetic diversity among } 48 \text { fenugreek genotypes which were } \\
\text { collected from different geographical regions of India using Inter Simple Sequence Repeat markers. } \\
\text { Totally twenty ISSR primers were screened among which, ten primers gave good amplification and } \\
\text { revealed a total of } 48 \text { polymorphic bands with an average of } 4.8 \text { bands per primer. The percentage of } \\
\text { polymorphism ranged from } 75.00 \% \text { (UBC-842) to } 100 \% \text { (UBC-851). Highest Polymorphic } \\
\text { Information Content (PIC) value was obtained in primers UBC-842 and UBC- } 860 \text { among ten } \\
\text { primers these proved best to assess the genetic diversity in fenugreek. UPGMA dendrogram } \\
\text { presented into } 10 \text { clusters at } 0.75 \text { similarity coefficient. The similarity coefficient ranging from } 0.59 \\
\text { to } 1.00 \text {. Principal component analysis confirmed the results of UPGMA. The genotypes from one } \\
\text { region were grouped together in some cases, while they were placed in different clusters in certain } \\
\text { cases. The measures of relative genetic distances among varieties of fenugreek did not completely } \\
\text { correlate with the geographical distances of their development. And the genotypes which are falling } \\
\text { in different groups indicate the presence of genetic diversity between the members of different } \\
\text { clusters. Crossing can be made between the members of different clusters for further crop } \\
\text { improvement, as they are genetically diverse. }\end{array}$} \\
\hline $\begin{array}{l}\text { Fenugreek, } \\
\text { Diversity, ISSR, } \\
\text { UPGMA, PIC. }\end{array}$ & \\
\hline Article Info & \\
\hline $\begin{array}{l}\text { Accepted: } \\
29 \text { May } 2017 \\
\text { Available Online: } \\
\text { 10 June } 2017\end{array}$ & \\
\hline & \\
\hline
\end{tabular}

\section{Introduction}

The genus Trigonella is one of the largest genera of the tribe Trifoliatae in the family Fabaceae and sub-family Papilionaceae (Balodi et al., 1991). Among Trigonella species, Trigonella foenum-graecum L. commonly known as fenugreek is a flowering annual with autogamous white flowers occasionally visited by insects. Indigenous to countries on the eastern shores of Mediterranean, fenugreek is widely cultivated in India, Egypt, Ethiopia, Morocco and occasionally in England (Polhil et al., 1981). Trigonella foenum-graecum $\mathrm{L}$. is extensively grown in the tropical and subtropical regions of India. Different parts of the plant such as leaves and seeds are consumed in India and are also utilized for medicinal purpose. In India, during 2011-12 this crop occupied an area of 0.93 lakh hectares and produced 1.13 lakh MT seed spice with productivity of 1.2 MT per hectare (Anonymous, 2014).

However, in view of the low production potential of traditional fenugreek varieties, there is dire need of improvement in this crop 
and the major objective lies in the development of new varieties with high yield and improved yield attributing traits. For any crop improvement the basic requirement is availability of germplasm with wide variability. Assessment of genetic divergence in fenugreek germplasm is important for long term crop improvement programme. Undoubtedly, the study of the genetic diversity of fenugreek genotypes is not only important for germplasm conservation but also in selecting the parents for breeding purposes. The morphology of plant is influenced by environment and developmental stages of crop, in this context the molecular markers provide a very accurate tool for evaluating genetic diversity of crop germplasm that focuses on understanding the genetic relationship among different
1. RajendraKranti
13. НM-208
2. $\mathrm{RM}-194$
14. HМ-221
3. $\mathrm{RM}-188$
15. HМ-239-1
4. GM-1
16. НМ-242
5. GM-2
17. НM-246
6. JFG-235
18. НМ-257
7. JFG-266
19. HM-258-1
8. HM-57
20. HM-273
9. HM-65
21. HM-281
10. HM-103
22. HM-291
11. HM-114
23. HM-307
12. HM-205
24. HM-332

\section{Genomic DNA isolation}

Genomic DNA was isolated from young leaves of 48 fenugreek genotypes following CTAB (Cetyl trimethyl ammonium bromide) extraction method as given by Murray and Thompson (1980) and modified by SaghaiMaroof et al., (1984). The quality and quantity of isolated genomic DNA was estimated by UV Spectrophotometer accessions of fenugreek. These markers are not influenced by environment as well as the plant development stages and are also very less time consuming compared to the morphological characterization.

\section{Materials and Methods}

\section{Plant material}

Forty eight fenugreek genotypes were collected from different parts of the country i.e., Andhra Pradesh, Bihar, Delhi, Gujarat, Haryana, Rajasthan and Uttar Pradesh. The seeds were sown in protraysunder polyhouse and young leaves were collected for DNA extraction. List of 48 genotypes used for molecular characterization are as follows:
25. HM-343
37. HM-528
26. HM-346
38. HM-536
27. HM-348
39. HM-548
28. HM-355
40. HM-555
29. HM-359
41. PEB-1
30. HM-444
42. LFC-93
31. HM-502
43. AFG-5
32. HM-507
44. AFG-6
33. НM-509
45. UM-202
34. HM-517
46. UM-354
35. HM-519
47. NDM-69
36. HM-526
48. NDM-72

(A260/A280 absorbance) and the DNA was also tested by submerged horizontal agarose $(0.8 \%)$ gel electrophoresis.

\section{Polymerase chain reaction (PCR) amplification}

Totally twenty ISSR primers were used for divergence studies (Table 1). PCR amplification was carried out in touch down 
Q-thermo cycler. The PCR reactions were carried out in $23.5 \mu \mathrm{l}$ of reaction mixture containing $13.5 \mu \mathrm{l}$ of sterile distilled water, $2.5 \mu \mathrm{l}(10 \mathrm{x}$ colorless buffer) reaction buffer, $2 \mu \mathrm{l} \quad \mathrm{dNTP} \quad(500 \mu \mathrm{l} \quad \mathrm{dNTP}$ of concentation $10 \mathrm{mM}+500 \mu \mathrm{l}$ of sterile distilled water), $2 \mu \mathrm{l}$ of $\mathrm{Mgcl}_{2}(25 \mathrm{Mm}), 2 \mu \mathrm{l}$ of primer $(10 \mu \mathrm{l}$ primer $+90 \mu \mathrm{l}$ of nuclear free water), $1 \mu$ l template DNA and $0.5 \mu \mathrm{l}$ of Taq DNA polymerase $(5 \mathrm{U} / \mu \mathrm{l})$. These were added into PCR tube in same sequence as above. In PCR amplification program for initial denaturation $4 \mathrm{~min}$ at $94^{\circ} \mathrm{C}$, followed by 36 cycles of $1 \mathrm{~min}$ at $94^{\circ} \mathrm{C}$ for denaturation, annealing temperature varied according to primer, $72^{\circ} \mathrm{C}$ for $2 \mathrm{~min}$ and for final extension $72^{\circ} \mathrm{C}$ for $8 \mathrm{~min}$ is followed.

Amplified DNA fragments were resolved by submerged horizontal agarose gel electrophoresis in $1.5 \%$ (w/v) agarose gel and visualized by staining with ethidium bromide.

Agarose solution was prepared in $1 \mathrm{X}$ TBE and ethidium bromide $(10 \mathrm{mg} / \mathrm{ml})$ was added in the gel at a concentration of $3 \mu \mathrm{l}$ per $100 \mathrm{ml}$ of gel and then mixed gently. It was poured in gel casting tray with appropriate comb with required well number and size. PCR products were mixed with loading dye and loaded into wells.

The gel was run at the voltage of 100 watts for 1 hour and is seen under UV light for presence of bands. And photo was taken in gel documentation system.

\section{Allele scoring}

ISSR amplification profiles were scored visually, based on presence (taken as 1) or absence (taken as 0) of bands for each genotype. Only clear and unambiguous bands were scored. The size of amplified bands was determined based on its migration relative to standard molecular weight markers.

\section{Cluster analysis}

The scored band data was subjected to statistical analysis using the computer programme NTSYS (version 2.02).

\section{Results and Discussion}

Primer selection and polymorphism exhibited

Among the twenty ISSR primers ten primers amplified unambiguous, readable and reproducible polymorphic bands. A total of 59 amplification products were produced from the selected 10 primers out of which 48 bands were polymorphic. The number of bands varied from 4 to 9 and the size ranged from 200 to $1500 \mathrm{bp}$. The highest number of bands (9) obtained in primer UBC-860, while the lowest number of bands (4) was observed with primer UBC-851 with an average of 5.9 bands per primer. Highest number of polymorphic bands (7) was observed in primer UBC-860 and the lowest number of polymorphic bands (4) was observed in primer UBC-807, UBC-834, UBC-840, UBC851, UBC-845 and UBC-850. The percentage of polymorphism ranged from 75.00 to $100 \%$ with an average of $83.15 \%$ polymorphism per primer. Primer UBC-851 revealed the highest polymorphism (100\%), whereas the primer UBC-842 exhibited the lowest polymorphism $(75.00 \%)$. The polymorphic information content (PIC) value ranged from 0.56 to 0.86 . Highest PIC value was obtained in primers UBC-842 and UBC-860 and the lowest PIC value was obtained with the primerUBC-851. The details are presented in table 2. It clearly indicated that the primers used in the present study contributed moderate to high as far as PIC is concerned. Their relative contribution is assessed accordingly and must be utilized in the light of PIC value. So, the primers UBC-842 and UBC-860 among ten primers proved best to 
assess the diversity in fenugreek. Similar results were reported by Harish et al., (2011), Nidhal et al., (2009) and Tomar et al., (2014). Since there was no relationship between the total number of bands generated by a primer and amount of polymorphism produced, we cannot assign the ranking to a particular primer simply based upon the total number of bands it produces. In literature there is no report indicating the existence of any such correlation.

Table.1 ISSR primers used in present investigation

\begin{tabular}{|c|c|c|c|}
\hline S. No. & Primer code & Primer sequence & Length \\
\hline 1 & UBC-807 & AGAGAGAGAGAGAGAGT & 17 \\
\hline 2 & UBC-834 & AGAGAGAGAGAGAGAGYT & 18 \\
\hline 3 & UBC-835 & AGAGAGAGAGAGAGAGYC & 18 \\
\hline 4 & UBC-838 & TATATATATATATATARC & 18 \\
\hline 5 & UBC-840 & GAGAGAGAGAGAGAGAYT & 18 \\
\hline 6 & UBC-841 & GAGAGAGAGAGAGAGAYC & 18 \\
\hline 7 & UBC-842 & GAGAGAGAGAGAGAGAYG & 18 \\
\hline 8 & UBC-843 & CTCTCTCTCTCTCTCTRA & 18 \\
\hline 9 & UBC-844 & СTCTCTCTCTCTCTCTRC & 18 \\
\hline 10 & UBC-845 & СTCTCTCTCTCTCTCTRG & 18 \\
\hline 11 & UBC-850 & GTGTGTGTGTGTGTGTYC & 18 \\
\hline 12 & UBC-851 & GTGTGTGTGTGTGTGTYG & 18 \\
\hline 13 & UBC-852 & TCTCTCTCTCTCTCTCRA & 18 \\
\hline 14 & UBC-856 & ACACACACACACACACYA & 18 \\
\hline 15 & UBC-857 & ACACACACACACACACYG & 18 \\
\hline 16 & UBC- 858 & TGTGTGTGTGTGTGTGRT & 18 \\
\hline 17 & UBC-860 & TGTGTGTGTGTGTGTGRA & 18 \\
\hline 18 & UBC-882 & VBVATATATATATATAT & 17 \\
\hline 19 & UBC-894 & TGGTAGCTCTTGATCANNNNN & 21 \\
\hline 20 & UBC-896 & AGGTCGCGGCCGCNNNNNNATG & 22 \\
\hline
\end{tabular}


Table.2 Polymorphism exhibited by ISSR primers in fenugreek genotypes

\begin{tabular}{|c|c|c|c|c|c|c|c|c|c|}
\hline $\begin{array}{l}\text { Sr. } \\
\text { No. }\end{array}$ & $\begin{array}{l}\text { Primer } \\
\text { code }\end{array}$ & $\begin{array}{c}\text { Primer sequence } \\
5^{\prime}<-------->3^{\prime}\end{array}$ & Length & $\begin{array}{c}\text { Total } \\
\text { number } \\
\text { of } \\
\text { bands }\end{array}$ & $\begin{array}{c}\text { Number of } \\
\text { monomorphic } \\
\text { bands }\end{array}$ & $\begin{array}{l}\text { Number of } \\
\text { polymorphic } \\
\text { bands }\end{array}$ & $\begin{array}{l}\text { Polymorphis } \\
\text { m }(\%)\end{array}$ & PIC & $\begin{array}{c}\text { Molecular } \\
\text { weight range } \\
\text { (bp) }\end{array}$ \\
\hline 1. & UBC-807 & AGAGAGAGAGAGAGAGT & 17 & 5 & 1 & 4 & 80.00 & 0.78 & $500-1000$ \\
\hline 2. & UBC-834 & AGAGAGAGAGAGAGAGYT & 18 & 5 & 1 & 4 & 80.00 & 0.79 & $300-950$ \\
\hline 3. & UBC-840 & GAGAGAGAGAGAGAGAYT & 18 & 5 & 1 & 4 & 80.00 & 0.77 & $300-1000$ \\
\hline 4. & UBC-841 & $\begin{array}{c}\text { GAGAGAGAGAGAGAGAY } \\
\text { C }\end{array}$ & 18 & 6 & 1 & 5 & 83.33 & 0.74 & $200-1000$ \\
\hline 5. & UBC-851 & GTGTGTGTGTGTGTGTYG & 18 & 4 & 0 & 4 & 100.00 & 0.56 & $700-1200$ \\
\hline 6. & UBC-842 & $\begin{array}{c}\text { GAGAGAGAGAGAGAGAY } \\
\text { G }\end{array}$ & 18 & 8 & 2 & 6 & 75.00 & 0.86 & $200-1000$ \\
\hline 7. & UBC-843 & СТСТСТСТСТСТСТСТRA & 18 & 7 & 1 & 6 & 85.71 & 0.84 & $600-1000$ \\
\hline 8. & UBC-845 & СТСТСТСТСТСТСТСТRG & 18 & 5 & 1 & 4 & 80.00 & 0.74 & $400-1000$ \\
\hline 9. & UBC-850 & GTGTGTGTGTGTGTGTYC & 18 & 5 & 1 & 4 & 80.00 & 0.78 & $450-1000$ \\
\hline 10. & UBC-860 & TGTGTGTGTGTGTGTGRA & 18 & 9 & 2 & 7 & 87.50 & 0.86 & $300-1500$ \\
\hline \multicolumn{4}{|c|}{ Total } & 59 & 11 & 48 & & & \\
\hline \multicolumn{4}{|c|}{ Average } & 5.9 & 1.1 & 4.8 & 83.15 & & \\
\hline
\end{tabular}


Table.3 Clustering of 48 fenugreek genotypes using ISSR at 0.75 similarity coefficient

\begin{tabular}{|c|c|c|}
\hline Clusters & $\begin{array}{c}\text { No. of } \\
\text { genotypes }\end{array}$ & Genotypes \\
\hline I & 2 & HM-332, HM291. \\
\hline II & 1 & AFG-6. \\
\hline III & 1 & PEB-1. \\
\hline IV & 9 & $\begin{array}{l}\text { HM-343, HM-517, HM-359, UM-354, HM-205, HM-528, UM-202, HM-242, } \\
\text { HM-526. }\end{array}$ \\
\hline $\mathrm{V}$ & 1 & R. Kranti. \\
\hline VI & 7 & HM-502, HM-281, HM-114, HM-273, NDM-69, NDM-72, HM-519. \\
\hline VII & 1 & HM-57. \\
\hline VIII & 1 & HM-555. \\
\hline IX & 18 & $\begin{array}{l}\text { HM-346, HM-65, HM-348, LFC-93, RM-188, RM-194, HM-103, HM-257, } \\
\text { HM-307, HM-355, HM-258-1, HM-239-1, GM-1, HM-208, HM-221, HM- } \\
\text { 246, HM-507, HM-548. }\end{array}$ \\
\hline $\mathrm{X}$ & 6 & HM-509, HM-444, JFG-235, AFG-5, JFG-266, GM-2. \\
\hline
\end{tabular}

Fig.1 Dendrogram generated using ISSR markers in 48 fenugreek genotypes

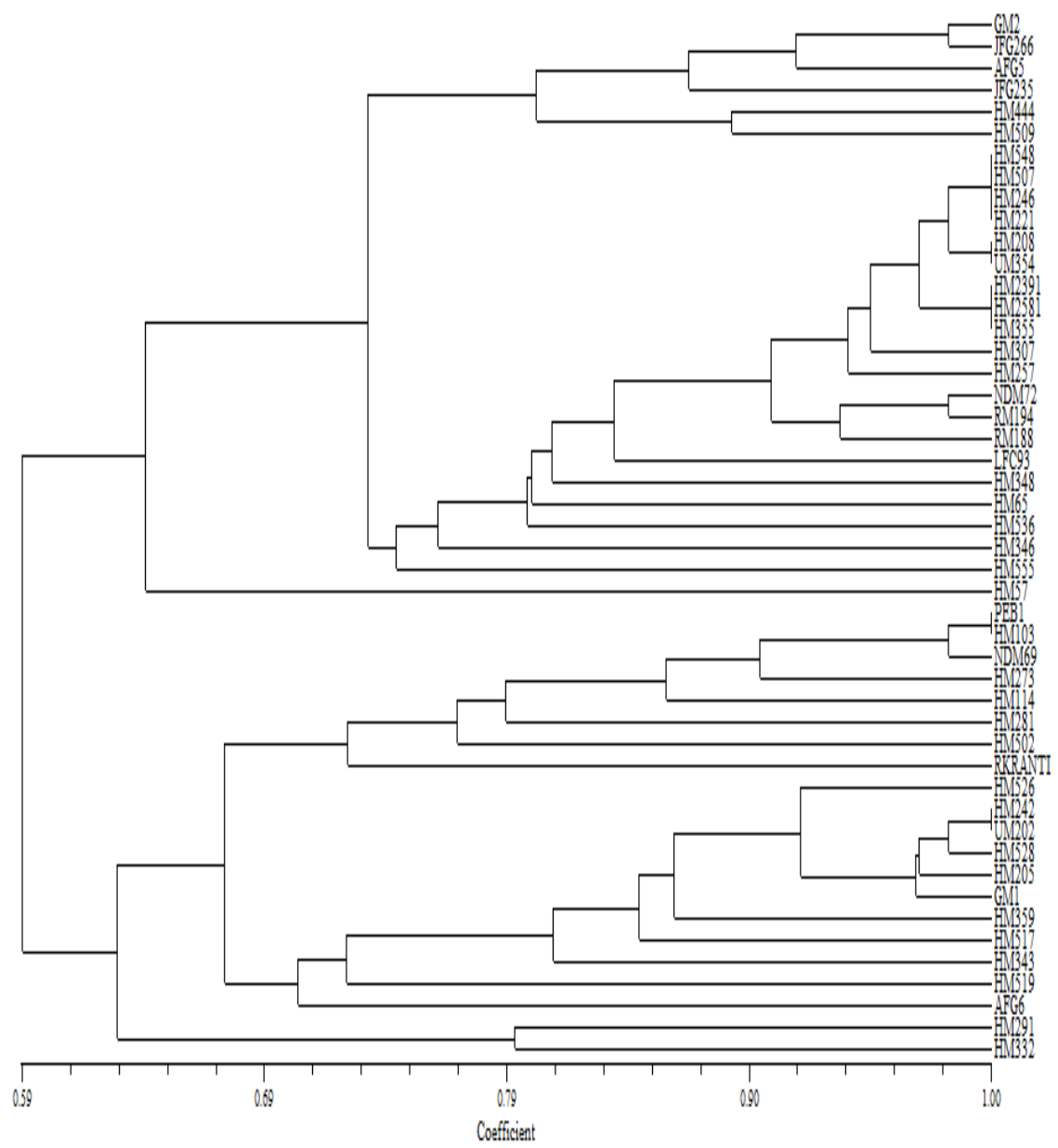


Fig.2 Two dimensional PCA scaling of 48 fenugreek genotypes using ISSR

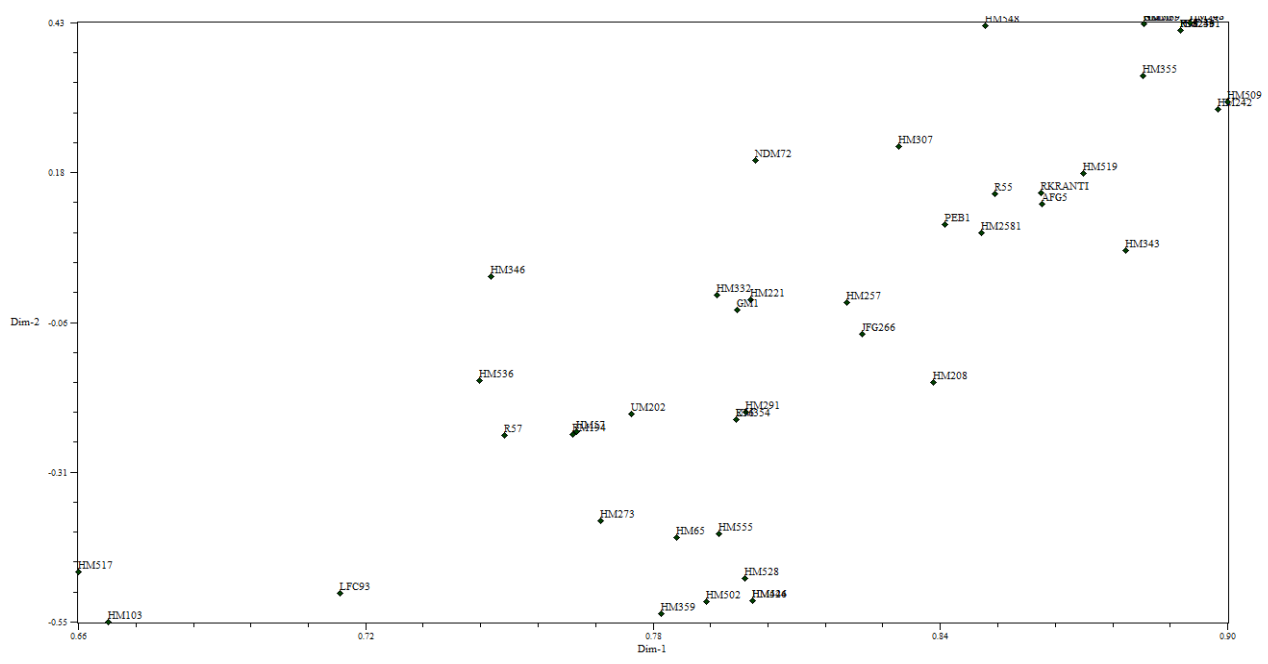

Fig.3 Three dimensional PCA scaling of 48 fenugreek genotypes using ISSR

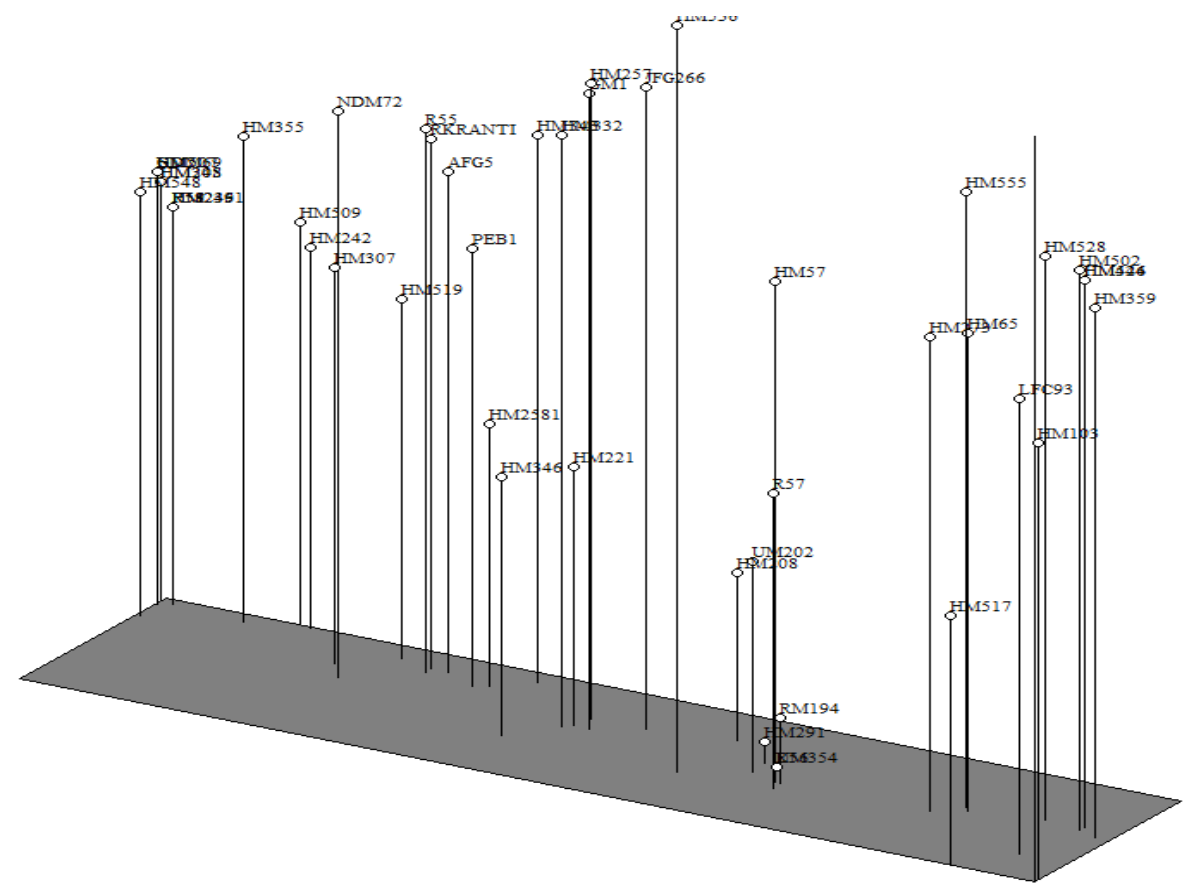

\section{Cluster analysis}

Molecular data obtained using 10 ISSR primers was used to construct dendrogram which, divided the fenugreek genotypes into 10 clusters (Table 3 ) at 0.75 similarity coefficient (Fig. 1). The two dimensional as well as three dimensional PCA scaling are presented in figures 2 and 3 respectively. The similarity co-efficient ranging from 0.59 to 1.00 . The genotypes from one region were grouped together in some cases, while they were placed in different clusters in certain cases. The clusters containing genotypes from same region maybe due to their pedigree relationship or they may be 
selected from same breeding population. The measures of relative genetic distances among varieties of fenugreek did not completely correlate with the geographical distances of places of their development. And the genotypes which are falling in different groups indicate the presence of genetic diversity between the members of different clusters. Crossing can be made between the members of different clusters as they are genetically diverse. These results were in agreement with the findings of Harish et al., (2011), Nidhal et al., (2009) and Tomar et al., (2014).

In conclusion present study gave the clear picture of existence of diversity in genotypes at genetic level as DNA markers are not influenced by environmental effects or plant growth stages whereas morphological markers does. ISSR markers proved best for assessing genetic diversity in fenugreek germplasm. This shows that the genotypes which were used in the present study can be utilized for further crop improvement programme.

\section{References}

Anonymous, (2014), Indian Horticulture Database. www.nhb.gov.in.

Balodi, B. and Rao, R. R. (1991). The genus Trigonella L. (Fabaceae) in theNorthwest Himalaya. J Econ Tax But,5(1):11-16.

Harish, Gupta, A. K., Ram, K., Singh, B., Mahendra, P. and Shekhawat, N. S.

\section{How to cite this article:}

Mamatha, N.C., S.K. Tehlan, M. Srikanth, T. Ravikumar, Shikha Yashveer and Mukesh Kumar. 2017. Assessment of Genetic Diversity among Fenugreek (Trigonella foenum-graecum L.) Genotypes using ISSR Markers. Int.J.Curr.Microbiol.App.Sci. 6(6): 2565-2572. doi: https://doi.org/10.20546/ijcmas.2017.606.305
(2011), Molecular and biochemical characterization of different accessions of Fenugreek (Trigonella foenumgraecum L.). Libyan Agril. Res. Center J. Intl., 2(3):150-154.

Murray, M. G. and Thompson, W. F. (1980), Rapid isolation of high molecular weight plant DNA. Nucleic Acids Research, 8: 4321-4326.

Nidhal, M., Anissa, B., Walid, E., Ferdaous, G., Leila, L., Ali, F., Tebra, T. and Mohamed, B. (2009), Assessment of genetic diversity in Trigonella foenum-graecum Tunisian cultivars using ISSR markers. J. of Food, Agri. \& Environment,7(1): 101-105.

Polhil, R. M. and Raven, P. H. (1981), Advances in legume systematic. RoyalBotanical Gardens, Kew, England, 2:23-28.

Saghai-Maroof, M. A., Soliman, K. M., Jorgensen, R. A. and Allard, R. W. (1984), Ribosomal DNA spacer-length polymorphism in Barley: Mendelian inheritance, Chromosomal-location and population dynamics. Proceedings of the National Academy of Sciences, 81: 8014-8019.

Tomar, R. S., Parakhia, M. V., Rathod, V. M., Thakkar, J. R. and Golakiya, B. A. (2014),A Comparative analysis of ISSR and RAPD markers for studying genetic diversity in Trigonella foenum-graecum genotypes. Res. J. Biotech,9(10): 89-95. 